\title{
Correction to: Fe3C nanoparticle formation in Fe implanted HOPG and CVD diamond
}

\section{Krishanlal Bharuth-Ram ${ }^{1,2}$ (D) $\cdot$ Hilary Masenda ${ }^{3} \cdot$ Carsten Ronning $^{2,4} \cdot$ Hans Hofsäss $^{5}$}

Published online: 5 September 2019

(C) Springer Nature Switzerland AG 2019

\section{Correction to: Hyperfine Interact https://doi.org/10.1007/s10751-019-1615-6}

Due to technical constraints this article was published in volume 240:1 with erroneous article citation ID number 6 whereas this should have been $\mathbf{7 6}$ which is corrected as such. Springer Nature sincerely apologizes towards the author(s) for the inconvenience caused.

Publisher's note Springer Nature remains neutral with regard to jurisdictional claims in published maps and institutional affiliations.

This article is part of the Topical Collection on Proceedings of the International Conference on Hyperfine Interactions and their Applications (HYPERFINE 2019), Goa, India, 10-15 February 2019

Edited by S. N. Mishra, P. L. Paulose and R. Palit

The online version of the original article can be found at https://oi.org/10.1007/s10751-019-1615-6

Krishanlal Bharuth-Ram

kbr@tlabs.ac.za

1 School of Chemistry and Physics, University of KwaZulu-Natal, Durban 4041, South Africa

2 Physics Department, Durban University of Technology, Durban 4000, South Africa

3 School of Physics, University of the Witwatersrand, Johannesburg 2050, South Africa

4 Institute for Solid State Physics, Friedrich-Schiller University of Jena, Jena, Germany

5 Second Physics Institute, University of Göttingen, Göttingen, Germany 